\title{
A Field Study on Fertility and Purity of Sex-Sorted Cattle Sperm
}

\author{
I. Cerchiaro, M. Cassandro, R. Dal Zotto, P. Carnier, and L. Gallo' \\ Department of Animal Science, University of Padova, 35020 Legnaro, Italy
}

\begin{abstract}
The study assessed the fertility and purity of sexed semen used for inseminating Holstein-Friesian heifers in commercial dairy herds. Sex-sorted semen from 4 proven Holstein-Friesian bulls and available under commercial conditions was used on nulliparous Holstein heifers reared on 61 dairy farms of northern Italy. Data from 536 artificial inseminations with pregnancy diagnosis and 258 calvings were analyzed using the logistic regression procedure. The effects of year and season of insemination or calving, age at insemination or calving, heifer inbreeding, and the sperm dose used for insemination on the probability of a positive pregnancy diagnosis or of the birth of a female calf, respectively, were studied. The overall pregnancy rate for sexed semen was $51 \%$ and was affected by year of insemination and bull. Heifers inseminated with sexed semen from 2 bulls had lower pregnancy rates than heifers inseminated with sexed semen from other bulls. Purity of the sexed sperm, based on the proportion of female calves, was $87 \%$ and this percentage was not affected by explanatory variables included in the logistic regression. The results demonstrate that bulls differ in terms of fertility of their sexed semen. Careful selection of the insemination sires used for sorted semen is advisable for avoiding low fertility inseminations.
\end{abstract}

Key words: sex-sorted sperm, fertility, purity, cattle

\section{INTRODUCTION}

Sperm sexing is an assisted reproductive technology that can increase the efficiency of breeding programs in dairy herds (Weigel, 2004). Several practical advantages have been suggested for sexed sperm, such as the reduction in the number of cows needed for progeny testing, the opportunity of using fewer and genetically better cows for producing replacement dairy heifers and a wider opportunity for crossbreeding of dairy cows with both dairy or beef bulls (Hohenboken, 1999; Seidel, 2002).

Received October 10, 2006.

Accepted January 26, 2007.

${ }^{1}$ Corresponding author: luigi.gallo@unipd.it
Several procedures have been proposed for sexing sperm, such as albumin gradient separation, sex-specific antibody binding, multitube swim-up, fractionation on a discontinuous Percoll gradient, and free-flow electrophoresis (Joerg et al., 2004). At present, the fastest, most reliable, and potentially most cost-effective procedure for sperm sexing is flow cytometry (Garner et al., 1983; Welch and Johnson, 1999; Seidel and Garner, 2002). This is the only routine procedure for sexing cattle sperm that is currently available for practical applications (Maxwell et al., 2004).

Live offspring from sperm sorted by flow cytometry were first obtained by surgically inseminating rabbit does into the oviduct (Johnson et al., 1989). Later, offspring of predetermined sex were produced in pigs (Rath et al., 1997), horses (Buchanan et al., 2000; Lindsey et al., 2002), and humans (Fugger et al., 1998). The production of calves by using sex-sorted sperm was reported by Cran et al. (1993, 1995), who combined this technology with in vitro fertilization and embryo transfer. Tubman et al. (2004) reported no difference between calves from sexed sperm and calves from control sperm for birth weight, calf vigor, weaning weight, and death rates (neonatal and through weaning) and no difference between cows inseminated with sorted sperm and cows inseminated with conventional sperm for gestation length, abortion rate, and calving ease.

Practical use of sexed sperm by commercial dairy herds depends on several factors, but fertility and accuracy of sex selection (i.e., purity) are probably the most important traits for evaluating the reliability of the technology. Lower pregnancy rates after insemination with sexed sperm have been reported for several species (Seidel and Garner, 2002) but data for the fertility of sexed sperm when used under field conditions are still scarce. Likewise, the purity of sexed sperm has been evaluated using laboratory procedures (Welch and Johnson, 1999) but studies on this outcome under practical conditions after insemination of dairy cows are limited. This field study assessed fertility and purity of sexed sperm used for inseminating Holstein-Friesian heifers reared in commercial dairy herds.

\section{Sources of Data}

\section{MATERIALS AND METHODS}

Heifer identity code and birth date, date of AI, sperm dose, and breeding bull identity code were recorded on 
536 nulliparous Holstein heifers that were reared in 61 dairy herds of northern Italy and were inseminated between September 2002 and April 2004. Heifers were inseminated with sperm produced by 4 proven Holstein sires (A, B, C, and D), sexed by Cogent (Chester, UK) through flow cytometry, and available under commercial conditions. Inseminations were done with either full straw, containing approximately $2 \times 10^{6}$ sperm, or half straw, containing $1 \times 10^{6}$ sperm. Heifers returning to estrus were diagnosed as not pregnant, whereas heifers that did not return to estrus were diagnosed pregnant with ultrasonography or rectal palpation. Calving date and calf sex were recorded at parturition. Inbreeding coefficients were provided by the Italian Holstein Breeders Association (ANAFI). Overall, 536 records of AI with pregnancy diagnosis and 258 calvings provided with a calf sex registration were available for this study.

\section{Statistical Analysis}

Statistical analysis was performed using logistic regression to investigate the influence of a set of explanatory variables on pregnancy rate and sex ratio. The effect of the investigated set of explanatory variables on the outcome of the insemination has been evaluated using estimates and confidence intervals of odds ratio (OR), a multiplicative measure of probability that ranges from 0 to infinity. Values of $\mathrm{OR}>1$ or $\mathrm{OR}<1$ indicate an increased or decreased probability of a positive pregnancy diagnosis or of a female calf birth, respectively, in comparison with a "reference condition" summarized by the intercept of the logistic regression model.

To estimate OR, logistic regression analysis was performed using the LOGISTIC procedure of SAS (SAS Institute, 1999-2001) according to the following model:

$$
\begin{gathered}
\ln \left[\frac{\pi(x)}{1-\pi(x)}\right]=\mu+b_{1} \mathrm{YEAR}+\sum_{i=1}^{3} b_{2 i} \mathrm{SEASON}_{i} \\
+\sum_{j=1}^{2} b_{3 j} \mathrm{AGE}_{j}+\sum_{k=1}^{2} b_{4 k} \mathrm{INBR}_{k}+b_{5} \mathrm{DOSE}+\sum_{l=1}^{3} b_{6 l} \mathrm{BULL}_{l}
\end{gathered}
$$

where $\ln \left[\frac{\pi(x)}{1-\pi(x)}\right]$ is the logit of $x(x=1$ for positive pregnancy diagnoses or occurrences of a female calf birth, $x=0$ for negative pregnancy diagnoses or occurrences of a male calf birth), and $\pi(x)$ is the probability of a positive pregnancy diagnosis or of a female calf birth; $\mu$ is the intercept of the model expressing the reference animal; that is, a heifer of the highest class of inbreeding (inbreeding $>5.0 \%$ or inbreeding $>4.5 \%$ for analysis of fertility or purity, respectively) and age at insemination (age $>590 \mathrm{~d}$ ) or at delivery (age $>850$ d), inseminated with half a semen dose (half straw containing $1 \times 10^{6}$ sperm) of bull $\mathrm{D}$ in winter or calving in autumn of the first year of trial; YEAR is an indicator variable with a value of 1 when the insemination or calving occurred in the second year of trial for the analysis of pregnancy rate or the analysis of purity, respectively; $\mathrm{SEASON}_{i}$ is an indicator variable with a value of 1 when the insemination or calving occurred in season $i$ ( $i=1$, from March to May; $i=2$, from June to August; $i=$ 3 , from September to November); $\mathrm{AGE}_{j}$ is an indicator variable with a value of 1 when the insemination (analysis of fertility) or the calving (analysis of purity) occurred at age $j$ (for analysis of fertility $j=1$, age $<450$ $\mathrm{d} ; j=2$, age from 450 to $590 \mathrm{~d}$; for analysis of purity $j=1$, age $<730 \mathrm{~d} ; j=2$, age from 730 to $850 \mathrm{~d}$ ); $\mathrm{INBR}_{k}$ is an indicator variable with a value of 1 when the inbreeding of the heifer was of class $k$ (for analysis of fertility $k=1$, inbreeding $<1.5 \% ; k=2$, inbreeding from 1.5 to $5.0 \%$; for analysis of purity $k=1$, inbreeding $<1.66 \%$; $k=2$, inbreeding from 1.66 to $4.50 \%$ ); DOSE is an indicator variable with a value of 1 when a whole straw was used for insemination; $\mathrm{BULL}_{l}$ is an indicator variable with a value of 1 when the semen used for insemination was from bull $l(l=1$, semen from bull A; $l=2$, semen from bull $\mathrm{B} ; l=3$, semen from bull $\mathrm{C}$ ).

\section{RESULTS AND DISCUSSION}

The pregnancy rate obtained using sexed cattle sperm in field conditions was slightly greater than $50 \%$ (Table 1). The pregnancy rate of sexed sperm observed in this trial was similar to that obtained with sexed semen in several trials reviewed by Weigel (2004), which ranged from 48 to 57\%. Fertility of sexed semen was considerably higher in this trial than in the study by Seidel and Schenk (2002), who reported a conception rate ranging from 31 to $46 \%$.

Fertility of sexed semen is typically lower than that of conventional semen (Weigel, 2004). The lower fertility is caused by the lower insemination dose $\left(2 \times 10^{6}\right.$ vs. 10 to $20 \times 10^{6}$ spermatozoa) and also by physical and chemical stresses that occur during the sorting process. These stresses include high dilution of gametes, staining with the DNA binding dye Hoechst 33342 , mechanical forces during sorting, light from the UV laser beam, and projection into the collection tube under high pressure and centrifugation (Garner, 2006). A direct comparison of fertility obtained using sexed or unsexed sperm was not possible in the present study because field data were used and unsexed sperm from the same bulls was not available. The reduction of fertility resulting from the use of sexed sperm, however, has been observed by Seidel et al. (1999), who reported 
Table 1. Pregnancy rate and estimates of odds ratio for factors related to a positive pregnancy diagnosis obtained on heifers inseminated with sex-sorted semen

\begin{tabular}{|c|c|c|c|c|c|}
\hline Variable & $\mathrm{n}$ & $\begin{array}{l}\text { Percentage } \\
\text { pregnant }\end{array}$ & $P<$ & Odds ratio & $95 \% \mathrm{CI}^{1}$ \\
\hline Inbreeding & & & NS & & \\
\hline$>5.00 \%^{2}$ & 83 & 54.2 & & 1 & \\
\hline$<1.50 \%$ & 79 & 48.1 & & 0.948 & $0.499-1.800$ \\
\hline 1.50 to $5.00 \%$ & 374 & 51.1 & & 0.930 & $0.568-1.521$ \\
\hline Insemination year & & & 0.010 & & \\
\hline $2002^{2}$ & 146 & 56.8 & & 1 & \\
\hline 2003 & 390 & 48.9 & & 0.507 & $0.302-0.851$ \\
\hline Insemination season & & & NS & & \\
\hline Winter ${ }^{2}$ & 219 & 50.7 & & 1 & \\
\hline Spring & 152 & 53.9 & & 1.191 & $0.765-1.856$ \\
\hline Summer & 43 & 44.2 & & 0.819 & $0.412-1.630$ \\
\hline Autumn & 122 & 50.8 & & 0.680 & $0.398-1.159$ \\
\hline Insemination age & & & NS & & \\
\hline$>590 \mathrm{~d}^{2}$ & 75 & 48.0 & & 1 & \\
\hline$<450 \mathrm{~d}$ & 87 & 45.9 & & 0.820 & $0.431-1.560$ \\
\hline 450 to $590 \mathrm{~d}$ & 374 & 52.9 & & 1.161 & $0.689-1.955$ \\
\hline Sperm dose ${ }^{3}$ & & & NS & & \\
\hline Half straw ${ }^{2}$ & 47 & 44.7 & & 1 & \\
\hline Whole straw & 489 & 51.7 & & 1.357 & $0.727-2.534$ \\
\hline Breeding bull & & & 0.047 & & \\
\hline $\mathrm{D}^{2}$ & 161 & 59.0 & & 1 & \\
\hline A & 143 & 51.7 & & 0.672 & $0.418-1.079$ \\
\hline $\mathrm{B}$ & 95 & 43.1 & & 0.527 & $0.309-0.898$ \\
\hline $\mathrm{C}$ & 137 & 46.7 & & 0.559 & $0.347-0.901$ \\
\hline Overall & 536 & 51.1 & & & \\
\hline
\end{tabular}

pregnancy rates with sexed semen from 70 to $90 \%$ of those obtained with unsexed control semen.

With respect to factors investigated as possible sources of variation of pregnancy rate, only year of insemination $(P=0.010)$ and bull $(P=0.047)$ were statistically significant (Table 1). Heifers inseminated in 2003 had a lower pregnancy rates than heifers inseminated in 2002. Data collection started in the autumn of 2002. Several studies pointed out the negative effects caused by high humidity and high temperature on cattle fertility (Wolfenson et al., 2000). The year effect, therefore, may have arisen because inseminations in spring and summer were done only in 2003.

Heifers inseminated with sexed sperm from 2 sires (B and C), had lower pregnancy rates when compared with heifers inseminated with sex-sorted semen from bull D (Table 1). Differences in pregnancy rates among bulls are well documented in the literature for both unsexed (Donovan et al., 2003) and sexed semen (Seidel et al., 1997; Bodmer et al., 2005). These results suggest the need for careful selection of bulls based on accurate analysis of semen fertility under field conditions.

The breeding season and the age of heifers at AI did not affect conception rate (Table 2 ). These results agree partly with those reported by Donovan et al. (2003), who reported that pregnancy rate was not related to age at first service and was negatively influenced by the hot season in a field study on 601 nulliparous Holstein heifers. In our study, $44 \%$ of the heifers inseminated in the summer became pregnant and greater percentages of heifers inseminated in winter, spring, and autumn became pregnant. Perhaps the lack of statistical significance observed in this study for the season can be explained by the relatively low number of AI done in the summer (Table 1).

Inbreeding of heifers did not affect the conception rate (Table 1). This result does not agree with findings of Wall et al. (2005), who reported an unfavorable effect of inbreeding on several reproductive traits in a mixed population of Holstein and Friesian cattle. Conversely, Cassell et al. (2003) failed to identify a maternal inbreeding depression effect on 70-d nonreturn rate in a study of 50,613 Holstein cows.

Sperm dose did not affect pregnancy rate but there was a numeric advantage when whole straws were used (Table 1). Seidel et al. (1999) also reported a minimal difference in pregnancy rates after the use of $1.5 \times 10^{6}$ or $3.0 \times 10^{6}$ sex-sorted spermatozoa. The low number of services with the half sperm dose may have affected our ability to detect significant effects. 
Table 2. Percentage of female calves and odds ratio for factors related to the birth of a female calf estimated on calves obtained using sexed sperm

\begin{tabular}{|c|c|c|c|c|c|}
\hline Variable & $\mathrm{n}$ & $\begin{array}{l}\text { Percentage } \\
\text { of female } \\
\text { calves }\end{array}$ & $P<$ & Odds ratio & $95 \% \mathrm{CI}^{1}$ \\
\hline Inbreeding & & & NS & & \\
\hline$>4.50 \%{ }^{2}$ & 64 & 89.1 & & 1 & \\
\hline$<1.66 \%$ & 38 & 89.5 & & 1.196 & $0.318-4.500$ \\
\hline 1.66 to $4.50 \%$ & 156 & 85.9 & & 0.810 & $0.318-2.064$ \\
\hline Sperm dose $\mathrm{e}^{3}$ & & & NS & & \\
\hline Half straw ${ }^{2}$ & 21 & 90.5 & & 1 & \\
\hline Whole straw & 237 & 86.9 & & 0.600 & $0.126-2.858$ \\
\hline Breeding bull & & & NS & & \\
\hline $\mathrm{D}^{2}$ & 88 & 89.8 & & 1 & \\
\hline A & 69 & 88.4 & & 0.807 & $0.276-2.360$ \\
\hline B & 38 & 79.0 & & 0.433 & $0.143-1.311$ \\
\hline $\mathrm{C}$ & 63 & 87.3 & & 0.656 & $0.222-1.937$ \\
\hline Calving year & & & NS & & \\
\hline $2003^{2}$ & 176 & 88.1 & & 1 & \\
\hline 2004 & 82 & 85.4 & & 0.851 & $0.240-3.020$ \\
\hline Calving season & & & NS & & \\
\hline Autumn ${ }^{2}$ & 103 & & & 1 & \\
\hline Winter & 77 & 89.6 & & 1.477 & $0.453-4.816$ \\
\hline Spring & 24 & 75.0 & & 0.556 & $0.104-2.967$ \\
\hline Summer & 54 & 90.7 & & 1.653 & $0.516-5.295$ \\
\hline Calving age & & & NS & & \\
\hline$>850 \mathrm{~d}^{2}$ & 47 & 83.0 & & 1 & \\
\hline$<730 \mathrm{~d}$ & 40 & 87.5 & & 1.069 & $0.289-3.949$ \\
\hline 730 to $850 \mathrm{~d}$ & 171 & 88.3 & & 1.423 & $0.530-3.824$ \\
\hline Overall & 258 & 87.2 & & & \\
\hline
\end{tabular}

${ }^{1} \mathrm{CI}=$ confidence interval.

${ }^{2}$ Reference condition $=$ heifer with inbreeding $>4.50 \%$, age at calving $>850 \mathrm{~d}$, inseminated with half sperm dose of bull $\mathrm{D}$ and calving in autumn of the first year of trial.

${ }^{3}$ Sperm dose: half straw $=1 \times 10^{6}$ sperm $/$ dose; whole straw $=2 \times 10^{6} \mathrm{sperm} /$ dose.

The purity of sexed sperm was high and no effect included in the logistic regression model significantly affected the sex of newborn calves (Table 2). Results of sexed sperm purity obtained in the present study are in good agreement with the literature (Seidel and Garner, 2002) and provide a field demonstration that semen sorting is a reliable method for sex preselection in cattle.

\section{CONCLUSIONS}

The use of sperm sexed by flow cytometry to inseminate dairy heifers reared in a large group of commercial dairy farms yielded a pregnancy rate of nearly $50 \%$, with $87 \%$ female calves. Pregnancy rates depended on year and insemination sire. Careful selection of the insemination sire used for sorted semen will be necessary so that low-fertility inseminations are avoided on commercial dairy farms.

\section{ACKNOWLEDGMENTS}

The authors thank Ghislandi and Ghislandi (Bergamo, Italy) and Intermizoo S.p.A. (Padova, Italy) for providing the sex-sorted semen. This research was sup- ported by Azione Biotech III-Veneto Region (Del.CIPE 35-2005).

\section{REFERENCES}

Bodmer, M., F. Janett, M. Hässig, N. den Daas, P. Reichert, and R. Thun. 2005. Fertility in heifers and cows after low dose insemination with sex-sorted and non-sorted sperm under field conditions. Theriogenology 64:1647-1655.

Buchanan, B. R., G. E. Seidel, Jr., P. M. McCue, J. L. Schenk, L. A. Herickhoff, and E. L. Squires. 2000. Inseminations of mares with low numbers of either unsexed or sexed spermatozoa. Theriogenology 53:1333-1344.

Cassell, B. G., V. Adamec, and R. E. Pearson. 2003. Maternal and fetal inbreeding depression for 70-day nonreturn and calving rate in Holsteins and Jerseys. J. Dairy Sci. 86:2977-2983.

Cran, D. G., L. Johnson, N. G. A. Miller, D. Cochrane, and C. E. Polge. 1993. Production of bovine calves following separation of $\mathrm{X}$ - and Y-bearing sperm and in vitro fertilization. Vet. Rec. 132:40-41.

Cran, D. G., L. A. Johnson, and C. E. Polge. 1995. Sex preselection in cattle: A field trial. Vet. Rec. 136:495-496.

Donovan, G. A., F. L. Bennett, and F. S. Springer. 2003. Factors associated with first service conception in artificially inseminated nulliparous Holstein heifers. Theriogenology 60:67-75.

Fugger, E. F., S. H. Black, K. Keyvanfar, and J. D. Schulman. 1998. Birth of normal daughters after MicroSort sperm separation and intrauterine insemination, in vitro fertilization, or intracytoplasmic sperm injection. Hum. Reprod. 13:2367-2370.

Garner, D. L., B. L. Gledhill, D. Pinkel, S. Lake, D. Stephenson, M. A. Van Dilla, and L. A. Johnson. 1983. Quantification of the X- 
and Y-chromosome-bearing sperm of domestic animals by flow cytometry. Biol. Reprod. 28:312-321.

Garner, D. L. 2006. Flow cytometric sexing of mammalian sperm. Theriogenology 65:943-957.

Hohenboken, W. D. 1999. Applications of sexed semen in cattle production. Theriogenology 52:1421-1433.

Joerg, H., M. Asai, D. Graphodatskaya, F. Janett, and G. Stranzinger. 2004. Validating bovine sexed semen samples using quantitative PCR. J. Anim. Breed. Genet. 121:209-215.

Johnson, L. A., J. P. Flook, and H. W. Hawk. 1989. Sex preselection in rabbits: Live births from X and Y sperm separated by DNA and cell sorting. Biol. Reprod. 41:199-203.

Lindsey, A. C., J. L. Schenk, J. K. Graham, J. E. Bruemmer, and E. L. Squires. 2002. Hysteroscopic insemination of low numbers of nonsorted or flow-sorted spermatozoa. Equine Vet. J. 34:128-132.

Maxwell, W. M. C., G. Evans, F. K. Hollinshead, R. Bathgate, S. P. de Graaf, B. M. Eriksson, L. Gillan, K. M. Morton, and J. K. O'Brien. 2004. Integration of sperm sexing technology into the ART toolbox. Anim. Reprod. Sci. 82-83:79-95.

Rath, D., L. A. Johnson, J. R. Dobrinsky, G. R. Welch, and H. Niemann. 1997. Production of piglets pre-selected for sex following in vitro fertilization with $\mathrm{X}$ and $\mathrm{Y}$ chromosome-bearing spermatozoa sorted by flow cytometry. Theriogenology 47:795-800.

SAS Institute. 1999-2001. SAS User's Guide: Statistics. Version 8.2 ed. SAS Institute Inc., Cary, NC.

Seidel, G. E., Jr. 2002. Sexing sperm for beef and dairy cattle breeding. Pages 281-286 in Factors Affecting Calf Crop: Biotechnology of Reproduction. M. J. Fields, R. S. Sand, and J. V. Yelich, ed. CRC Press, Boca Raton, FL.
Seidel, G. E., Jr., C. H. Allen, L. A. Johnson, M. D. Holland, Z. Brink, G. R. Welch, J. K. Graham, and M. B. Cattell. 1997. Uterine horn insemination of heifers with very low numbers of nonfrozen and sexed spermatozoa. Theriogenology 48:1255-1264.

Seidel, G. E., Jr., and D. L. Garner. 2002. Current status of sexing mammalian spermatozoa. Reproduction 124:733-743.

Seidel, G. E., Jr., and J. L. Schenk. 2002. Field trials with sexed, frozen bovine semen. Pages 64-69 in Proc. 19th Tech. Conf. Artificial Insemination and Reproduction, Nat. Assoc. Anim. Breed., Columbia, MO.

Seidel, G. E., Jr., J. L. Schenk, L. A. Herickhoff, J. L. Schenk, S. P. Doyle, and Z. Brink. 1999. Insemination of heifers with sexed semen. Theriogenology 52:1407-1420.

Tubman, L. M., Z. Brink, T. K. Suh, and G. E. Seidel, Jr. 2004. Characteristics of calves produced with sperm sexed by flow cytometry/cell sorting. J. Anim. Sci. 82:1029-1036.

Wall, E., S. Brotherstone, J. F. Kearney, J. A. Woolliams, and M. P. Coffey. 2005. Impact of nonadditive genetic effects in the estimation of breeding values for fertility and correlated traits. J. Dairy Sci. 88:376-385.

Weigel, K. A. 2004. Exploring the role of sexed semen in dairy production systems. J. Dairy Sci. 87(E Suppl.):E120-E130.

Welch, G. R., and L. A. Johnson. 1999. Sex preselection: Laboratory validation of the sperm sex ratio of flow sorted X- and Y-sperm by sort reanalysis for DNA. Theriogenology 52:1343-1352.

Wolfenson, D., Z. Roth, and R. Meidan. 2000. Impaired reproduction in heat-stressed cattle: Basic and applied aspects. Anim. Reprod. Sci. 60-61:535-547. 